\title{
Weekly Physical Activity from IPAQ (Arabic) Recalls and from IDEEA Activity Meters
}

\author{
Nadia H. J. Garashi, J. Ramadan Al Kandari, Barbara E. Ainsworth*, M. Barac-Nieto \\ Health Sciences Center, Department of Physiology, Kuwait University, Jabriya, Kuwait \\ Email: Ramadan@hsc.edu.kw
}

How to cite this paper: Garashi, N.H.J., Al Kandari, J.R., Ainsworth, B.E. and Barac-Nieto, M. (2020) Weekly Physical Activity from IPAQ (Arabic) Recalls and from IDEEA Activity Meters. Health, 12, 598-611. https://doi.org/10.4236/health.2020.126045

Received: May 7, 2020

Accepted: June 8, 2020

Published: June 11, 2020

Copyright (อ 2020 by author(s) and Scientific Research Publishing Inc. This work is licensed under the Creative Commons Attribution International License (CC BY 4.0).

http://creativecommons.org/licenses/by/4.0/ (c) (i) Open Access

\begin{abstract}
Objective: Determine the Test reliability and the objective validity of the International Physical Activity Questionnaire (IPAQ). Methods: IPAQ was evaluated for test-retest reliability within $6-8$ days of its first administration. Criterion validity was tested comparing IPAQ data with those from an activity meter (Intelligent Device for Energy Expenditure and Activity, IDEEA). Results: The test-retest correlation $(n=71)$ for items of IPAQ ranged from $r$ $=0.63$ to $\mathrm{r}=0.74$ and was $\mathrm{r}=0.79$ for the total weekly PA in MET ${ }^{\star} \min$ per week. Average PA (in MET*min/week) measured with the IDEEA meter, decreased from normal $(15,840)$, to 14,278 in overweight $(\mathrm{BMI}>25-<30)$ and further to 12,803 in obese subjects $(>30$. BMI). The weekly energy expenditure measured by IDEEA correlated significantly $\left(r=0.61, r^{2}=0.38\right)$ with the IPAQ data, providing an objective criterion for validity of IPAQ. The mean values of weekly PA estimated from IPAQ (in $\mathrm{MET}^{\star} \mathrm{min} /$ week) differed significantly in the high $(15,690)$ vs. the low $(11,398)$ activity groups but not between the moderate $(12,056)$ compared to the low PA group. The IPAQ criteria used to categorize subjects as moderately active, erred by including too many low PA subjects. IDEEA measurements in sedentary subjects overestimated their energy expenditure. Conclusions: IPAQ can be reliably used to distinguish low and high PA groups and yields relatively low estimates $(-18 \%)$ of weekly PA in these groups compared to those measured with the activity meter. Stricter criteria are needed to distinguish moderate from low PA groups. Overweight and obese subjects showed significantly lower levels of PA than normal BMI subjects. IDEEA overestimates low levels of PA.
\end{abstract}

\section{Keywords}

Physical Activity, Energy Expenditure, International Recall Questionnaire, Validation, Relbility, Activity Meters, Obesity, Overweight

*Visiting Professorat Kuwait University and at Shanghai University of Sport, Department of Kinesiology. 


\section{Introduction}

1) Inactivity is widespread in Kuwait, the Gulf countries and in developed as well as in some sectors of developing countries [1]. Inactivity occurs at all socioeconomic levels and at all ages. Its consequences are dangerous to human health and well-being [1]. Modern technologies, both at work, school and recreational, favor sitting and lack of physical activity (PA). Child's physical fitness and daily levels of PA are declining worldwide, but more so in modern wealthy urban environments [2].

Obesity, type 2 diabetes, atherosclerosis and heart disease are all epidemic ([3] and are appearing at ever younger ages associated with the decline in aerobic fitness (for example ability to run) [4].

2) Valid reliable measurements of habitual PA are essential to monitor and evaluate public health issues as well as to assess the effects of interventions designed to improve the levels of PA and/or the physical fitness of population groups [5].

Several instruments are available to measure PA, including double labeled water decay [6], indirect calorimetry [7], movement sensors of various types [8], pedometers mono-axial to tri-axial, accelerometers and associated software [9], GPS telemetry [10], heart rate telemetry [11], direct observation and recording of physical activities and various types of self-report questionnaires [12]. Each has its limitations [12]. Most (double labeled water decay, calorimetric, movement sensors and heart rate meters) provide objective measures but are usually costly and impractical for use with large sample groups. Questionnaires are subjective, of varying reliability and are not always a valid measure of physical activity. Evaluations of self-administered 85 physical activity questionnaires for adults [13], 61 for youth [14], and 13 for the elderly have been recently documented [15] and shown varying levels of reliability and validity [15]. Two types of questionnaires have been used for international surveillance of PA.

The Global Phycal Activity Questionnaire (GPAQ) was developed by the World Health Organization [16] and asked about 3 different levels of physical activity: vigorous, moderate and walking across 3 domains: work-related (including home work), transportation-related and leisure-related for various periods (one week or more). It does not inquire about sitting time, an important modifiable, component of inactivity in modern societies.

3) The International Physical Activity Questionnaire (IPAQ) is the most widely currently used PA questionnaire in research studies [5] [13] [17]. It was developed to facilitate surveillance of PA based on a global standard [17]. The IPAQ in its short form (IPAQ-SF), recommended for national surveys, recalls physical activities periods of at least 10 min duration at four intensity levels: a) vigorous, such as running, b) moderate, such as tennis or aerobic dancing, c) walking, and d) sitting, for the last 7 days [17]. A recent review [18] concluded that the IPAQ-SF typically overestimated PA by an average of 84 percent and that there is "weak evidence to support the use of IPAQ-SF as an indicator of 
relative or absolute $\mathrm{PA}$ ".

4) Instruments to assess daily PA in the Arab world are not readily available and have not been adequately tested and validated. In the current study, an Arabic version of IPAQ-SF was developed and evaluated for test-retest reliability and for criterion validity by comparing it with measurements of physical activity (PA) obtained from activity meters (Intelligent Device for Energy Expenditure and Activity, IDEEA) with sensors and software able to identify positions, types and intensity of most human movements [19], already validated against direct calorimetry [20], and used in adult Kuwaiti subjects.

\section{Methods}

1) Study design, protocols and recruitment. This cross-sectional study targeted 40 Kuwaiti citizens from both genders of 17 - 65 years of age, students or government office workers. Potential participants (147) were contacted by the investigators, volunteered to participate, and were able to perform any physical activity, with no mental and loco-motor handicaps and no acute or chronic diseases. All subjects read and signed a consent form previously approved by $\mathrm{Ku}-$ wait University.

Subjects visited the Exercise Laboratory at Kuwait University twice. In the first visit they answered the first IPAQ-SF, were weighted and measured (Detecto Balance, Webb CiIy, MO), instructed and fitted with the IDEEA activity meter. In the second visit the IDEEA devise was downloaded, data were verified and the second IPAQ recall was filled.

2) To measure PA, the International Physical Activity Questionnaire Short Form, (IPAQ-SF) was translated into Arabic, culturally adapted, back translated and tested in a pilot study $(\mathrm{n}=145)$ where logistics of distribution, data entry, verification and analysis were evaluated (Table 1). IPAQ has a short form, for national monitoring, and a long form for research purposes. We used the self-administered short form of IPAQ (available at http://www.ipaq.ki.se/). It was translated to Arabic and back-translated. The items in the short IPAQ form are structured to provide separate scores on sitting, walking, moderate-intensity and vigorous-intensity physical activities with no domain (work, home, leisure,

Table 1. Correlations of IPAQ SF tests done at day 1 vs. at day 7.

\begin{tabular}{cccc}
\hline Item & Outcome & $(\mathrm{r})$ & P value \\
\hline IPAQ1 × IPAQ2 & Vigorous PA min/w & 0.74 & $<0.001$ \\
IPAQ3 $\times$ IPAQ4 & Moderate PA min/w & 0.631 & $<0.001$ \\
IPAQ5 × IPAQ6 & Walking min/w & 0.699 & $<0.001$ \\
All PA levels. & Total MET.min/w & 0.793 & $<0.001$ \\
\hline
\end{tabular}

For each level of physical activity, an uneven numbered IPAQ item (min/day) is multiplied by an even numbered IPAQ item (days/week) to compute the min/wk. spent in that particular physical activity level. The time/week spent in each activity times the MET cost of that activity (high $=8$, moderate $=4$ or walking $=3.3 \mathrm{METS}$ ) yields the $\mathrm{MET}^{\star} \mathrm{min} / \mathrm{wk}$. for that activity. The sum of the MET*min/wk. for all activities yields the total $\mathrm{MET}^{\star} \mathrm{min} / \mathrm{wk}$. spent in all recalled episodes of physical activity, lasting at least $10 \mathrm{~min}$ each. 
transportation) specific estimates. As recommended, the examples of vigorous and moderate PA given in the official English version of the short-form of IPAQ had to be culturally adapted to Kuwait. For example, digging and fast-bicycling are neither common nor popular types of vigorous PA among Kuwaitis. Thus, other examples such as running, soccer, volleyball and basketball were used instead. Similarly, examples of moderate PA used included aerobic dancing and table tennis (ping pong) rather than doubles-tennis originally cited in the English version of IPAQ. Throughout the IPAQ items, emphasis was made on the following points. The respondent is reminded to consider all four domains of PA (work, home, transportation, leisure) when answering. This was necessary to avoid the tendency of confining PA to leisure types of PA, reflecting the layman $\mathrm{i}$ mage of PA. Another important point stressed out was for respondents to think only of continuous PA bouts of at least 10 minutes duration. They were allowed to sum up these bouts. Emphasis was made to report any walking (brisk, rapid, in shopping, strolling) in the walking category and NOT TO report brisk, rapid walking as a moderate level activity, so as to not duplicate this activity. All these and other important points (inclusion criteria, careful and complete answers) were also summarized in an instruction sheet attached to the envelope which contained the questionnaire as a cover sheet. We felt it helped the subjects answer the questionnaire with less ambiguity. Other researchers alluded to similar practices in their experience with IPAQ elsewhere, especially in low- to moderate-education areas of the world (13). Subjects delivered the completed IPAQ-SF at the end of the week when they wore the IDEEA activity meter.

Computation of the total PA minutes per week requires multiplying the duration (in minutes/day) and the frequency (days/week) for walking, for moderate-intensity and vigorous-intensity bouts (of at least $10 \mathrm{~min}$ each). Energy expenditure can be calculated by multiplying the time/week for each type of activity by the Metabolic Equivalent (MET) intensity value for that activity yielding energy expended (in MET-minutes per week) for vigorous-intensity, moderate-intensity PA and walking. A MET is the energy cost of an activity relative to the resting metabolic rate $\left(3.5 \mathrm{ml} \mathrm{O}_{2} / \mathrm{kg}\right.$ per min).

IPAQ defines moderate physical activities as those that make breathing somewhat harder than normal. These are equivalent to 3 - 5.9 MET based on the Compendium of Physical Activity (11) but IPAQ uses a "representative" average of 4 MET for any moderate PA. Vigorous physical activities are defined as those making breathing much harder than normal (making one unable to carry a conversation easily). Their metabolic equivalent value is $\geq 6$ MET (11) but IPAQ uses an average of $8 \mathrm{MET}$ for any vigorous PA. In IPAQ, walking is assigned a value of 3.3 MET on average. IPAQ also asks to recall time for sedentary activities (sitting, lying down) during the previous seven days.

In addition, IPAQ allows categorical scores denoting one of three PA intensity levels (low, moderate and high) according to criteria related to MET-min per week (low $<600$, high $>1500$, moderate $>600$ to $<1500$ ). In the IPAQ-SF, low PA was defined as $<30 \mathrm{~min} /$ day of walking or moderate activity, 5 times/week, or 
$<20$ min of vigorous activity, 4 times/week, or combinations thereof yielding < $600 \mathrm{MET}^{\star} \mathrm{min} /$ week. High PA was defined as any combination of PAs yielding $>$ $1500 \mathrm{MET}^{\star} \mathrm{min} / \mathrm{w}$. About one third of all subjects participating in the study were included in each category.

The various activities reported in the IPAQ were assigned intensity values of 3.3 (walking), 4 (moderate) and 8 (vigorous) METS. These intensity values times the reported duration of each activity in min per week yielded the PA in $\mathrm{MET}^{\star} \mathrm{min} /$ week for each activity level. The sum of all the MET*min/week for all physical activity levels, yielded the total PA MET*min/week. Finally, the time in the week unaccounted for by recalled physical activities plus that reported sitting or lying down, was assigned a MET value of 1.1 (taken as the average intensity for all sedentary, inactive periods, including sleep and sitting) and the product added to the total PA MET*min/week to calculate the Grand Total MET*min expended per week, to be compared to that derived from the concurrently measured by the IDEEA activity meter.

3) Reliability. In a group of subjects $(n=71)$ the Arabic version of IPAQ were evaluated for test-retest reliability within 6 - 8 days of its first administration (see Table 1).

4) Objective Criterion validity was tested by comparing data from the Arabic version of IPAQ with measurements of PA obtained from an activity meter (Intelligent Device for Energy Expenditure and Activity, IDEEA). IDEEA [19] was worn day and night for a week (except while showering or bathing) by the 40 subjects who were instructed on how to set the electrodes, how to change the flash drive and how to turn on and off the recorder. IDEEA was used for an average of $6.44+/-0.3$ days in one week, by each of 40 adult Kuwaiti subjects(19 males and 21 females) free from any chronic disease or loco-motor disability and answered the IPAQ-SF and were categorized as of low, moderate or high intensity PA categories (13 or 14 subjects in each category).

The IDEEA recorder is a plastic box $7 \times 5.4 \times 1.7 \mathrm{~cm}$ worn on a belt which houses a ARM microprocessor, a flash memory (up to 4 days records) and an AA battery (of 48 - $72 \mathrm{~h}$ duration,) with the corresponding circuits. This is connected via $2 \mathrm{~mm}$ OD insulated flexible wires to 5 piezoelectric sensors attached with 3M Medipore 2963 tape, to the mid-sternum, the anterior mid-tights and under the arch of each foot. (Figure 1) Data in the Flash memory can be transferred to a Windows based PC with the IDEEA software and processed by an analysis and viewing program (ACTIVIEW), capable of identifying the signal patterns of more than 35 physical activities, their intensity, frequency and duration. [19] The IDEEA software allows calculation of the MET*min expended per week $(1 \mathrm{MET}=1 \mathrm{Kcal} / \mathrm{Kg} \cdot \mathrm{h})$ in all recorded activities and has been validated against direct calorimetry.

5) Statistics. Descriptive analysis was performed for all variables, showing means and standard error of the mean (SEM) and/or coefficient of variation (CV) for normally distributed values (normality detected using Kolmogorov 


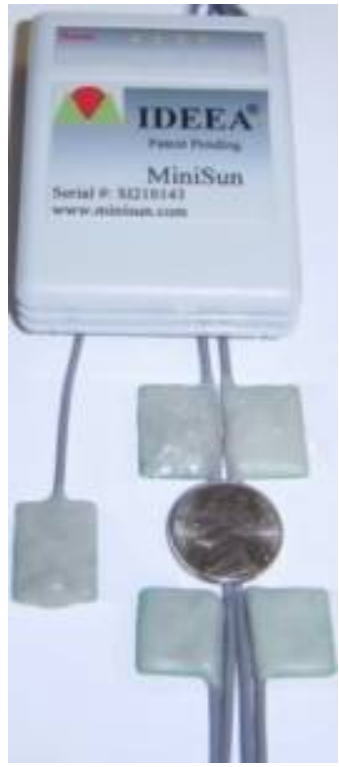

(a)

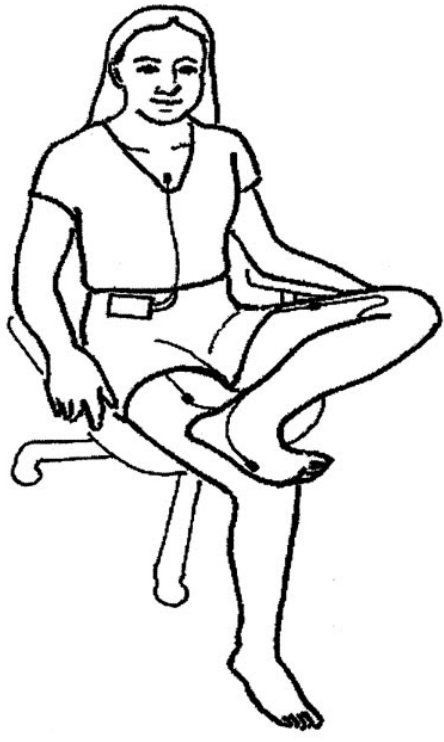

(b)

Figure 1. (a) IDEEA activity meter, showing recorder, wires and sensors, and (b) drawing of the position of the sensors on a subject from the IDEEA manual.

Smirnov test), or medians and quartiles otherwise. Frequency tables were created for categorical variables. For comparisons and associations of categorical variables, cross-tabulation with chi-square maximum likelihood and the exact probability Fisher tests were used. For continuous variables, ANOVA and t-tests were used in normally distributed data; the Mann-Whitney $U$ test and the Kruskal-Wallis tests were used for nonparametric data, as indicated in the text. Linear regressions, correlations and coeficients of determination, were estimated using the SPSS package.

\section{Results}

1) The BMI calculated from the height $(\mathrm{cm})$ and weight $(\mathrm{kg})$ reported in the IPAQ, were highly reliable and correlated highly $(r=0.98)$ with those directly measured in these subjects (Figure 2, $\mathrm{p}<0.01$ ).

2) Sitting time was $13+/-0.3 \mathrm{~h}$ by IDEEA measurements and significantly ( $P$ $<0.05)$ under-reported as $8+/-0.45 \mathrm{~h}$ in the IPAQ-SF recall questionnaire. The measured and reported sitting times were however significantly correlated $(r=$ 0.38 ).

3) The test-retest correlations for individual items of Physical Activity in the Arabic version of IPAQ ranged from 0.63 to 0.74 and was 0.79 for the total recalled weekly PA in MET*min per week (Table 1 ).

4) Using IDEEA, the average daily energy expenditure (EE $=2977 \mathrm{Kcal})$ was higher $(\mathrm{p}<0.05)$ in males than in females $(2373 \mathrm{Kcal})$, but it did not differ ( $\mathrm{p}>$ 0.1 ) by gender when expressed in METs (1.49 vs. 1.47) or in MET*min/week $(15,055$ vs. 14,781), variables which correct for differences in body weight (Figure 3). The IPAQ-SF derived weekly EE data (13,891 and 12,285 $\mathrm{MET}^{\star} \mathrm{min} /$ week for 
BMI

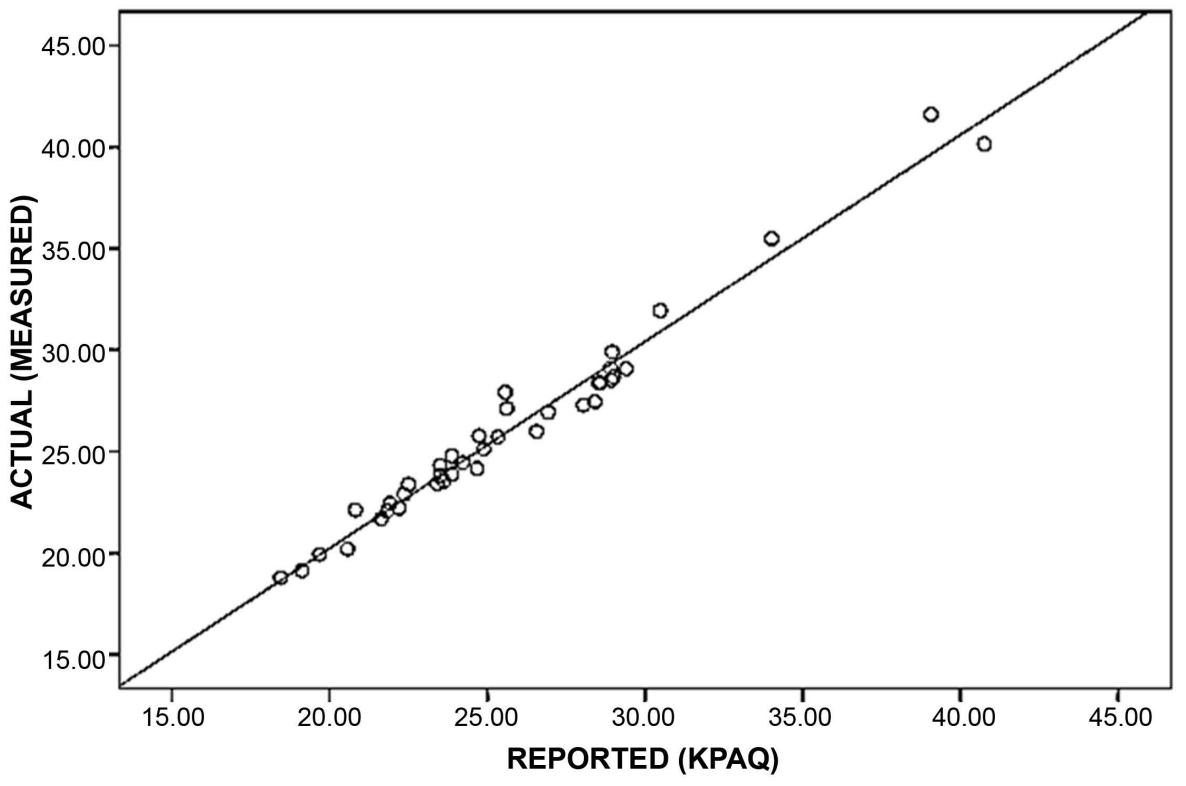

Figure 2. Correlation between BMI calculated from recall reported Height and Weight (KPAQ) and BMI from Height and Weight measured in the laboratory. $\mathrm{R}=0.987, \mathrm{r}^{2}=$ $0.974, \mathrm{n}=40$.

\section{MET.min/Wk by SEX and Method}

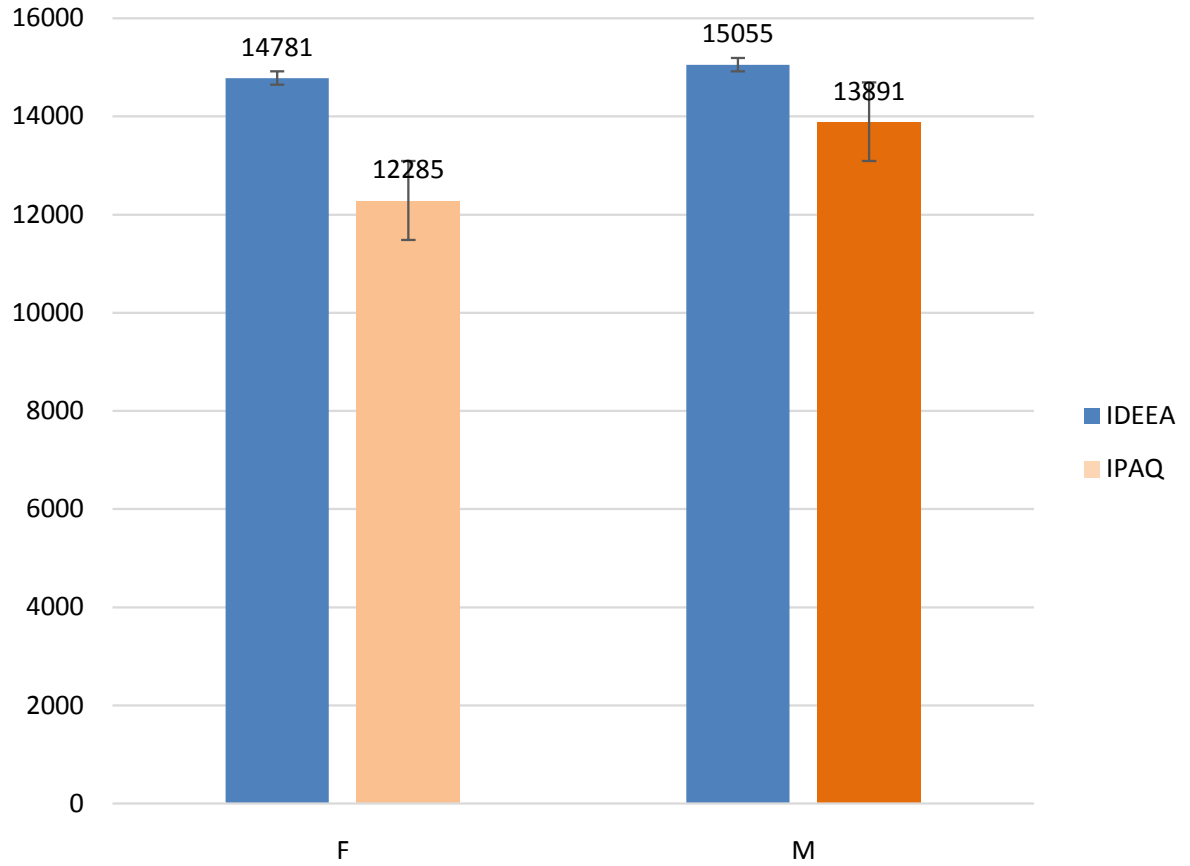

Figure 3. Mean $\mathrm{MET}^{\star}$ min/wk. from IDEEA measurements and from IPAQ recalls (corrected for sedentary activities by adding 1.1x (10080-total duration of recalled PA min/wk.), compared across sex. Although the IPAQ recall data (ocre) underestimated by about $18 \%$ the concurrently measured energy expenditure with the IDEEA recorders (blue), there were no significant differences between sexes neither in IDEEA measurements nor in IPAQ recalls. Error bars are 95\% confidence intervals. To calculate average intensity in METs divide the $\mathrm{MET}^{\star} \mathrm{min} / \mathrm{wk}$. by 10,080 min/wk. One MET = $1 \mathrm{Kcal} / \mathrm{kg} \cdot \mathrm{h}$. 
males and females, respectively) were significantly $(\mathrm{p}<0.05)$ lower than those found with the IDEEA sensors, but were not different $(p>0.1)$ from each other (Figure 3).

The average energy expediture (EE in $\mathrm{MET}^{\star} \mathrm{min} /$ week) measured with the IDEEA meter, decreased from 15,840 in subjects with normal BMI, to 14,278 in overweight subjects, to 12,803 in obese subjects (Figure 4). A similar tendency was identified using estimates of EE from IPAQ data averages (in METmin/week) and were 13,925, 12,459 and 11,518 in normal, overweight and obese subjects, respectively. In normal and overweight subjects the measured EE levels (IDEEA) were significantly higher $(p<0.01)$ than those reported in the IPAQ recall. However in the obese group, measured and reported EE levels did no differ significantly.

5) The weekly EE as measured by the IDEEA activity meter correlated significantly $\left(r=0.61\right.$, coefficient of determination $\left.r^{2}=0.38\right)$ with the total weekly PA data derived from the Arabic version of IPAQ (Figure 5) indicating a more than adequate objective criterion validity for this recall instrument.

6) Groups categorized as of high or low PA according to data in the IPAQ-SF survey, (Figure 6) showed distinctly and significantly different levels of weekly EE as measured by the IDEEA activity meters (16,131 vs. 14,162 METmin/week). By contrast, subjects categorized as of moderate PA (from their IPAQ-SF data) had a mean level of EE, measured by IDEEA (Figure 6), not different from that found in those categorized as of low PA (14,428 vs. 14,162 $\mathrm{MET}^{*} \mathrm{~min} /$ week), due mostly to an overestimate of the EE in the low activity group. The mean values of weekly EE estimated from IPAQ-SF (in MET*min/week), although lower in absolute value than found with IDEEA, also differed significantly in the high

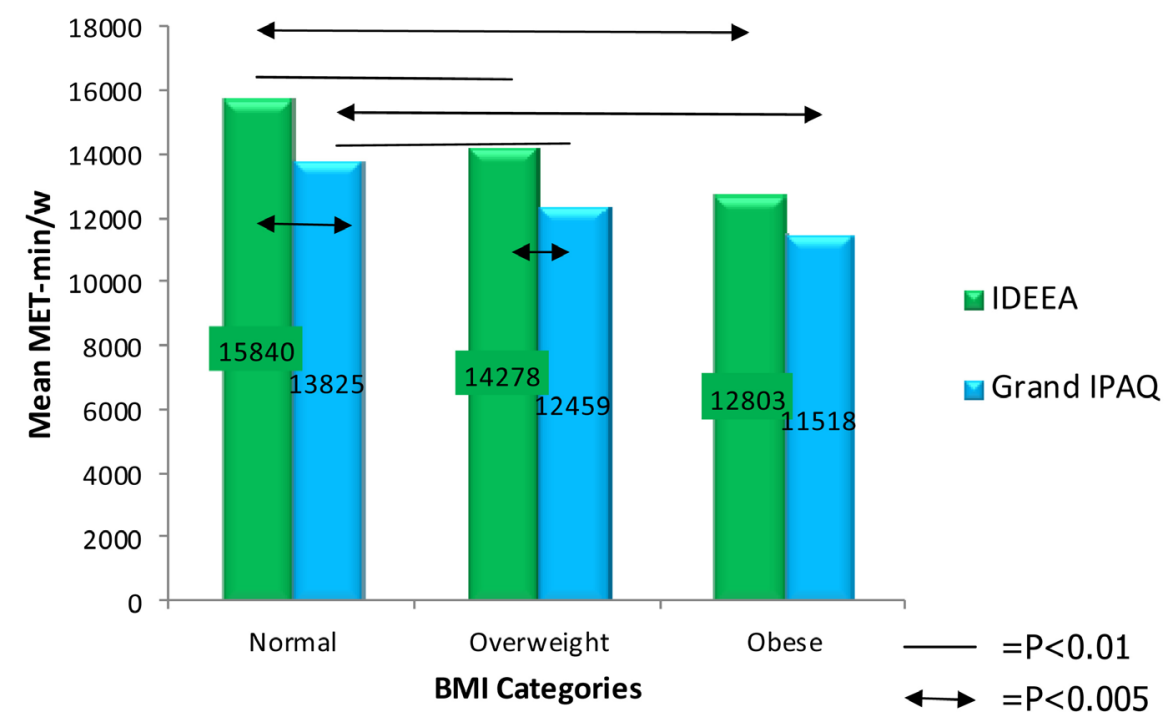

Figure 4. Energy expenditure in $\mathrm{MET}^{\star} \mathrm{min} / \mathrm{wk}$. from IDEEA measurements (blue), and from IPAQ (green) PA recalls (corrected for sedentary activities as explained in Figure 3 ), across BMI categories ( $<25=$ normal, $25-30=$ overweight, $>30$ obese $)$ calculated from measured Height and Weight. 


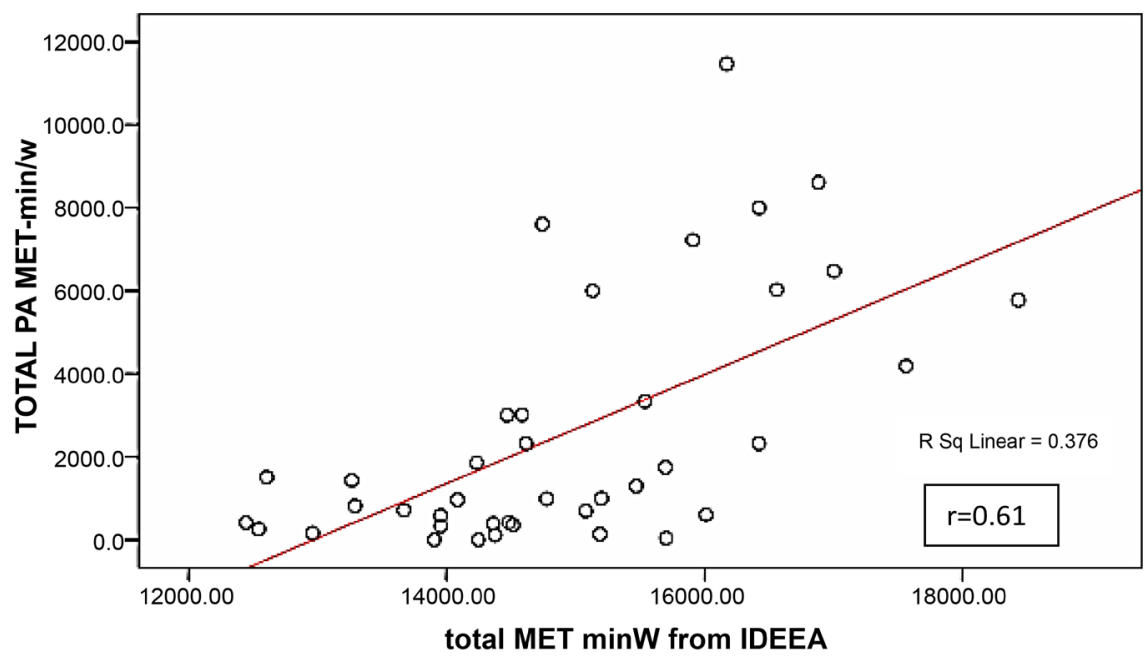

Figure 5. Correlation between IDEEA (X axis) measured weekly energy expenditure (in $\mathrm{MET}^{\star} \mathrm{min} / \mathrm{wk}$.) and IPAQ recalled (Y axis) weekly energy expenditure in all IPAQ reported (walking, moderate and high intensity) physical activities (TOTAL PA), also in $\mathrm{MET}^{\star} \min /$ wk. $\mathrm{r}=0.61, \mathrm{r}^{2}=0.38$.

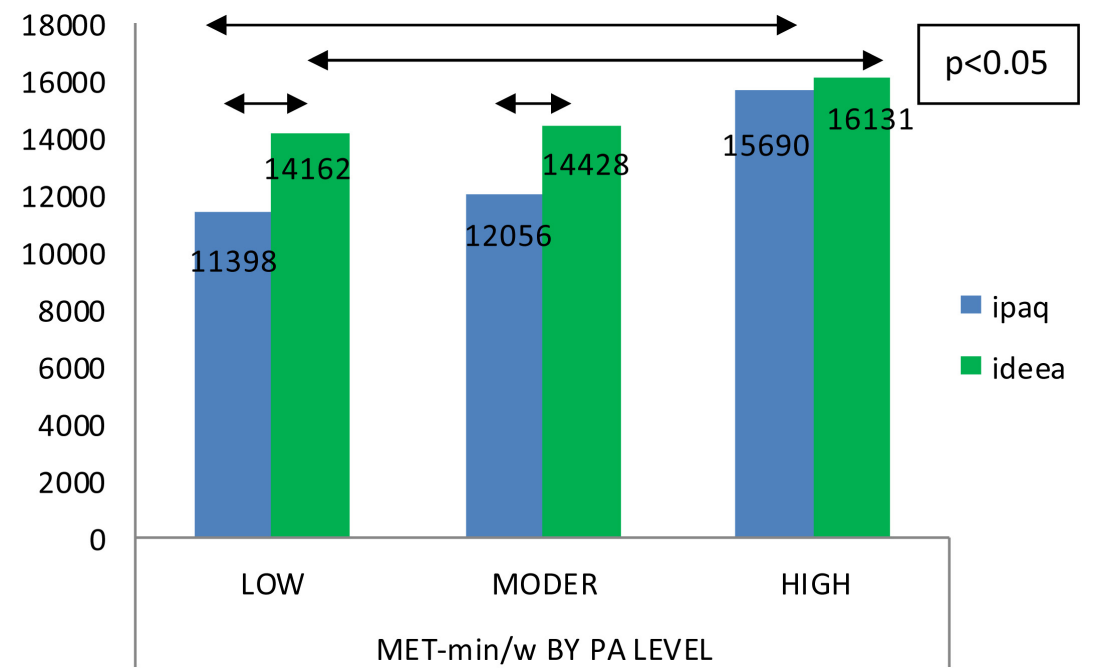

Figure 6. Energy expenditure in $\mathrm{MET}^{\star} \mathrm{min} / \mathrm{wk}$. from IDEEA measurements (blue) and from IPAQ (green) recalls (corrected for sedentary activities as explained in Figure 2), across categorical PA levels (Low, Moderate and High) derived from IPAQ recall data, according to the following criteria (High = any combination of physical activities adding to more than $1500 \mathrm{MET}^{\star} \mathrm{min} / \mathrm{wk}$.; Moderate = any combination of PA adding to 600 $1500 \mathrm{MET}^{*} \mathrm{~min} /$ week or walking at least for $30 \mathrm{~min} /$ day for 5 days/wk. or vigorous activities for at least $20 \mathrm{~min} /$ day and 3 days/wk.; Low = any combination of PA not meeting the above criteria).

$(15,690)$ and the low $(11,398)$ PA activity groups (Figure 6). For those in the moderate activity group $(12,056)$ IPAQ-SF derived weekly EE was not significantly different from that found in the low activity group (Figure 6). These findings indicate that IPAQ-SF underestimates the PA concurrently measured by IDEEA by about 18\%, but, high and low PA groups can be clearly differentiated. By contrast, the criteria used to categorize subjects as of moderate PA 
erred by including low PA subjects in the moderate activity group. Two of the criteria used: a) Five or more days of moderate intensity activities and or walking for at least $\mathbf{3 0}$ min per day, and b) Three or more days of vigorous activity for at least $\mathbf{2 0}$ min per day) yielded too low values in average METmin per week (495 and 480) and should be increased, the first to about $40 \mathrm{~min} /$ day, the second to $25 \mathrm{~min} /$ day. IPAQ recall data significantly underestimated the IDEEA measured weakly EE in the low and moderate activity groups but not in the more active group, suggesting that recall of vigorous activities is better than that of moderate and low intensity activities.

\section{Discussion}

1) The IPAQ-SF can be reliably used to distinguish low and high PA groups and yields relatively low estimates $(-18 \%)$ of weekly PA compared to those measured with the IDEEA activity meters, which detect some activities and NEAT (non-exercise related activities) which are not reported in IPAQ.

Total weekly PA derived from the data reported in IPAQ was significantly correlated with the weekly EE measured by IDEEA $(r=0.61)$, indicating that the developed Arabic version of IPAQ-SF serves as a useful tool in the assessment of physical activities in adult Kuwaiti subjects. The reliability of the IPAQ recall, as evaluated by test-retest correlation, was even higher $(r=0.79)$. According to Ferguson's [21] guidelines for interpretation of $r$, the value of $r=0.61$ found for the objective criterion validity data can be considered above average, while that for reliability $(r=0.79)$ can be considered high.

2) The correlation of 0.61 found between IDEEA objective weekly PA data and the IPAQ-SF recall data can be considered more than acceptable [22]. This value is higher than previously found between IPAQ-SF and various objective measures of physical activity [23] from accelerometers, pedometer or actimeters (highest value $r=0.39$ ) and may relate to the simultaneous, accurate and complete measurements of PA provided by IDEEA, the long recording time (nearly 7 days), heightened awareness of PA by simultaneously wearing the IDEEA device, and the high level of cooperation shown by the subjects.

In one criterion validity study using doubly labeled water [24], participants were categorized into insufficiently, sufficiently, and highly active based on their IPAQ-SF scores. Total energy expenditure (measured using doubly labeled water) was compared across the three categories. Energy expenditure in the highly active group was significantly higher than in the other two groups. Thus highly active participants could be correctly identified, but other discrimination was poor [24]. This is similar to our findings with IPAQ-SF and with IDEEA data which show average EE significantly more in the high than in the low PA groups.

3) Moderately Physically Active subjects, in the current study, were not distinguished from those in the low activity group. More strict, higher level of activity criteria is to be used to categorize moderate levels of physical activities 
(such as: Five or more days of any combination of walking, moderate or vigorous activities achieving a minimum of 600 but less than $1500 \mathrm{MET}^{\star} \mathrm{min} /$ week). In particular, the nature of brisk walking and the required increases in breathing and sweating should be emphasized to the subjects and distinguished from leisure, regular walking. If walking intensity cannot be increased, a longer period of daily leisure walking (40 min minimum) should be recommended.

The group with moderate activity had average EE as measured with IDEEA similar to that found in the low activity group. Thus IDEEA data overestimated the EE of the sedentary, low activity subjects which should be close to that at rest (about 1.1 MET rather than 1.4 as measured by IDEEA) but close to that estimated by the IPAQ recalls.

4) Overweight and obese subjects showed significantly lower levels of EE (in $\mathrm{MET}^{\star} \mathrm{min} /$ week) than normal BMI subjects, confirming the association of increased body weight with inactivity. The current study is unable to define whether excess weight leads to inactivity [25], Inactivity leads to excess weight [26] or both, because of lack of longitudinal data. IPAQ-SF recall data as well as objective IDEEA measurements successfully detected these weight-related differences in EE. The IDEEA meters overestimate the EE particularly in sedentary subjects [27].

5) The Major limitations of this study were:

a) Simultaneous objective PA measurements using IDEEA and PA estimated with recall IPAQ data.

b) relative difficulty of attaching the sensors.

c) inconvenience and discomfort of wearing the sensors.

d) limited memory capacity of IDEEA.

e) Need for high level cooperation of subjects for IDEEA measurements.

f) Relatively small number (40) of subjects evaluated.

g) No cycling activity done by the subjects nor measurable by IDEEA.

h) IPAQ Did Not sufficiently distinguish the EE of PA associated with moderate breathing from those with lower EE (such as leisure walking, standing, sitting or reclining).

i) IDEEA meters overestimate PA particular in sedentary subjects.

j) Lack of longitudinal data makes it impossible to define if inactivity leads to high BMI or if high BMI leads to inactivity.

6) In conclusion, major strengths and findings of this study are:

a) Objective measures of daily PA in Arabic subjects for the first time.

b) Reasonable quantitative estimates of daily PA using the IDEEA activity meter in high and moderate PA groups, but not in the low activity group where it is overestimated by IDEEA.

c) Reasonable estimates of daily PA, recalling duration of bouts of walking, of PA with moderate or heavy breathing, followed by MET conversions (IPAQ-SF).

Average Energy expenditure in subjects with high activity levels was significantly different from those with low activity levels. However, average Energy expenditure in moderately active subjects did not significantly differ from that in 
sedentary subjects, pointing to too lax criteria used in the definition of moderate activities and to high variance of the data.

d) Good correlation between IPAQ-SF and objective IDEEA measurements of EE.

e) Both IDEEA and IPAQ detected higher EE in subjects with normal BMI than in those with high BMI.

f) Higher EE in males than in females disappears when expressed per unit Body weight.

\section{Acknowledgements}

The authors acknowledged financial support of Kuwait University, Department of Physiology.

\section{Conflicts of Interest}

The authors declare no conflicts of interest regarding the publication of this paper.

\section{References}

[1] Lee, I.-M., Shiromq, E.J., Lobelo, F., Puska, P., Blair, S.N. and Katzmarzyk, P.T. (2012) Effect of Physical Inactivity on Major Non-Communicable Diseases Worldwide: An Analysis of Burden of Disease and Life Expectancy. The Lancet, 380, 219-229. https://doi.org/10.1016/S0140-6736(12)61031-9

[2] Yusuf, S., Reddy, S., Ôunpuu, S. and Anand, S. (2001) Global Burden of Cardiovascular Diseases. Part 1. General Considerations, the Epidemiologic Transition, Risk Factors and Impacts of Urbanization. Circulation, 104, 2746-2753. https://doi.org/10.1161/hc4601.099487

[3] World Health Organization (2002) The World Health Report 2002: Reducing Risks, Promoting Healthy Life. WHO, Geneva.

[4] World Health Organization (2004) WHO RESOLUTION. Global Strategy on Diet, Physical Activity and Health. http://www.who.int/dietphysicalactivity/strategy/eb11344/strategy english web.pdf

[5] Pereira, M.A., FitzerGerald, S.J., Gregg, E.W., Joswiak, M.L., Ryan, W.J., Suminski, R.R., Utter, A.C. and Zmuda, J.M. (1997) A Collection of Physical Activity Questionnaires for Health-Related Research. Medicine and Science in Sports and Exercise, 29, S1-205.

[6] Lifson, N., Gorden, G.B. and McClintock, R. (1955) Measurement of Total Carbon Dioxide Production by Mean of D218O. Journal of Applied Physiology, 7, 704-771. https://doi.org/10.1152/jappl.1955.7.6.704

[7] Maiolo, C., Melchiorri, G., Iacopino, L., Masala, S. and De Lorenzo, A. (2003) Physical Activity Energy Expenditure Measured Using a Portable Telemetric Device in Comparison with a Mass Spectrometer. British Journal of Sports Medicine, 37, 445-447. https://doi.org/10.1136/bjsm.37.5.445

[8] De Cocker, K.A., De Bourdeaudhuij, I.M. and Cardon, G.M. (2008) What Do Pedometer Counts Represent? A Comparison between Pedometer Data and Data from Four Different Questionnaires. Public Health Nutrition, 12, 74-81. https://doi.org/10.1017/S1368980008001973 
[9] Plasqui, G. and Westerterp, K.R. (2007) Physical Activity Assessment with Accelerometers: An Evaluation against Double Labeled Water. Obesity, 15, 2371-2379. https://doi.org/10.1038/oby.2007.281

[10] Worringham, C., Rojek, A. and Stewart, I. (2011) Development and Feasibility of a Smartphone, ECG and GPS Based System for Remotely Monitoring Exercise in Cardiac Rehabilitation. PLOS ONE, 6, e14669.

https://doi.org/10.1371/journal.pone.0014669

[11] Spurr, G.B., Prentice, A.M., Murgatroyd, P.R., Goldberg, G.R., Reina, J.C. and Christman, N.T. (1988) Energy Expenditure from Minute-by-Minute Heart-Rate Recording: Comparison with Indirect Calorimetry. The American Journal of Clinical Nutrition, 48, 552-559. https://doi.org/10.1093/ajcn/48.3.552

[12] Haskell, W.L. and Kiernan, M. (2000) Methodologic Issues in Measuring Physical Activity and Physical Fitness When Evaluating the Role of Dietary Supplements for Physically Active People. The American Journal of Clinical Nutrition, 72, 541S-550S. https://doi.org/10.1093/ajcn/72.2.541S

[13] Van Poppel, M.N.M., Chinapaw, M.J.M., Mokkink, L.B., van Mechelen, W. and Terwee, C.B. (2010) Physical Activity Questionnaires for Adults: A Systematic Review of Measurement Properties. Sports Medicine, 40, 565-600. https://doi.org/10.2165/11531930-000000000-00000

[14] Chinapaw, M.J.M., Mokkink, L.B., van Poppel, M.N.M., van Mechelen, W. and Terwee, C.B. (2010) Physical Activity Questionnaires for Youth: A Systematic Review of Measurement Properties. Sports Medicine, 40, 539-563. https://doi.org/10.2165/11530770-000000000-00000

[15] Forsen, L., Loland, N.W., Vuillemin, A., Chinapaw, M.J.M., van Poppel, M.N.M., Mokkink, L.B., van Mechelen, W. and Terwee, C.B. (2010) Self-Administrated Physical Activity Questionnaires for the Elderly: A Systematic Review of Measurement Properties. Sports Medicine, 40, 601-623. https://doi.org/10.2165/11531350-000000000-00000

[16] Bull, F.C., Maslin, T.S. and Armstrong, T. (2009) Global Physical Activity Questionnaire (GPAQ): Nine Country Reliability and Validity Study. Journal of Physical Activity and Health, 6, 790-804. https://doi.org/10.1123/jpah.6.6.790

[17] Lee, P.H., Macfarlane, D.J., Lam, T.H. and Stewart, S.M. (2011) Validity of the International Physical Activity Questionnaire Short Form (IPAQ-SF): A Systematic Review. International Journal of Behavioral Nutrition and Physical Activity, 8, Article No.: 11. http://www.ijbnpa.org/content/8/1/11 https://doi.org/10.1186/1479-5868-8-115

[18] Scheeres, K., Knoop, H., van der Meer, J. and Bleijenberg, G. (2009) Clinical Assessment of the Physical Activity Pattern of Chronic Fatigue Syndrome Patients: A Validation of Three Methods. Health and Quality of Life Outcomes, 7, 29. https://doi.org/10.1186/1477-7525-7-29

[19] Zhang, K., Werner, P., Sun, M., Pi-Sunyer, F.X. and Boozer, C.N. (2003) Measurement of Human Daily Physical Activity. Obesity Research, 11, 33-40. https://doi.org/10.1038/oby.2003.7

[20] Zhang, K., Pi-Sunyer, F.X. and Boozer, C.N. (2004) Improving Energy Expenditure Estimation for Physical Activity. Medicine \& Science in Sports \& Exercise, 36, 883-889.

[21] Ferguson, C.J. (2009) An Effect Size Primer: A Guide for Clinicians and Researchers. Professional Psychology: Research and Practice, 40, 532-538. https://doi.org/10.1037/a0015808 
[22] Terwee, C.B., Mokkink, L.B., van Poppel, M.N.M., Chinapaw, M.J.M., van Mechelen, W. and de Vet, H.C.W. (2010) Qualitative Attributes and Measurement Properties of Physical Activity Questionnaires: A Checklist. Sports Medicine, 40, 525-537. https://doi.org/10.2165/11531370-000000000-00000

[23] Lee, P.H., Macfarlane, D.J., Lam, T.H. and Stewart, S.M. (2011) Validity of the International Physical Activity Questionnaire Short Form (IPAQ-SF): A Systematic Review. International Journal of Behavioral Nutrition and Physical Activity, 8, Article No.: 115.

[24] Ishikawa-Takata, K., Tabata, I., Sasaki, S., Rafamantananatsoa, H.H., Okazaki, H., Okibo, H., Tanaka, S., Yamamoto, S., Shirota, T., Uchida, K. and Murata, M. (2008) Physical, Activity Level in Healthy Free-Living Japanese Estimated by Doubly Labelled Water Method and International Physical Activity Questionnaire. European Journal of Clinical Nutrition, 62, 885-891. https://doi.org/10.1038/sj.ejcn.1602805

[25] Metcalf, B.S., Hosking, J., Jeffery, A.N., Voss, L.D., Henley, W. and Wilkin, T.J. (2010) Fatness Leads to Inactivity, but Inactivity Does Not Lead to Fatness: A Longitudinal Study in Children. Archives of Disease in Childhood, 96, 942-947. https://doi.org/10.1136/adc.2009.175927

[26] Pietiläinen, K.H., Kaprio, J., Borg, P., Plasqui, G., Yki-Järvinen, H., Kujala, U.M., Rose, R.J., Westerterp, K.R. and Rissanen, A. (2008) Physical Inactivity and Obesity: A Vicious Circle. Obesity (Silver Spring), 16, 409-414. https://doi.org/10.1038/oby.2007.72

[27] Whybrow, S., Ritz, P., Horgan, G.W. and Subbs, R.J. (2012) An Evaluation of the IDEEA $^{\mathrm{Tm}}$ Activity Monitor for Estimating Energy Expenditure. The British Journal of Nutrition, 109, 173-183. https://doi.org/10.1017/S0007114512000645 